\title{
A GREEN METHOD TO PRODUCE BIODIESEL FROM PALM OLEIN OIL
}

\author{
NUWAN A PANNILAWITHANA* and HEMA M K K PATHIRANA*
}

\begin{abstract}
The current transesterification method to produce biodiesel from palm oil uses $\mathrm{NaOH}$ as the homogeneous catalyst. $\mathrm{NaOH}$ has several disadvantages. It is corrosive, can not be reused, and separation from biodiesel is time-consuming. The objective of the present work was to replace $\mathrm{NaOH}$ with a greener and efficient heterogeneous catalyst, calcium diglyceroxide. The potential contamination of biodiesel by $\mathrm{Ca}^{2+}$ was minimised by incorporating $\mathrm{Na}_{2} \mathrm{CO}_{3}$ into the transesterification mixture. The work aimed to identify the optimum reaction conditions which would minimise the production cost of biodiesel complying with the quality prescribed by ASTM standards. Optimum conditions were oil: methanol ratio of 1:6 (molar), catalyst $0.2 \%$ ( $w / w$ oil), $\mathrm{Na}_{2} \mathrm{CO}_{3} 2.5 \%$ ( $\mathrm{w} / \mathrm{w}$ oil), and $3 \mathrm{hr}$ reaction period at $65^{\circ} \mathrm{C}$. The yield was $92.2 \%$. All the studied properties of biodiesel except kinematic viscosity conformed with recommended levels by ASTM. Reusing the catalyst which was used twice previously, increased the biodiesel yield from $92.2 \%$ to 94.3\%. The production of good quality biodiesel from palm olein by this novel method is greener. It is more efficient because the catalyst is not corrosive and easy to separate. Also, the catalyst can be reused at least twice, thus minimising the amounts of chemicals used.
\end{abstract}

Keywords: palm olein oil, biodiesel, transesterification, heterogeneous catalyst, calcium diglyceroxide.

Date received: 26 June 2016; Sent for revision: 30 June 2016; Received in final form: 13 March 2017; Accepted: 26 April 2017.

\section{INTRODUCTION}

Biodiesel is considered as a greener alternative to petrodiesel. This is because it is renewable and biodegradable. Unlike petrodiesel, biodiesel emissions are not harmful to the environment. It consists of a mixture of monoalkylesters of long- chain fatty acids produced from the transesterification of triglycerides in vegetable oils, animal fats or waste cooking oil in the presence of alcohol as a catalyst. The by-product of the transesterification reaction is glycerol. In order to use biodiesel as an alternative fuel, the quality of biodiesel should comply with the recommended standards, while the cost of

Department of Chemistry,

University of Ruhuna, Wellamadama Matara,

Matara Southern 81000,

Sri Lanka.

E-mail: hpathirana@gmail.com production should be less than or comparable with that of petrodiesel. In the transesterification process, methanol is normally used as the alcohol and either $\mathrm{NaOH}$ or $\mathrm{KOH}$ is used as the homogeneous base catalyst. There are certain challenges associated with this procedure; $\mathrm{NaOH}$ is a corrosive chemical which cannot be reused, a large volume of wastewater is released when separating $\mathrm{NaOH}$ from biodiesel, treatment of the effluent is expensive and procedure is time-consuming (Granados et al., 2010; Alba Rubio et al., 2012, Lee et al. 2015). A promising solution to mitigate such challenges is to develop and use a greener catalyst which can be easily recovered and make possible the use of minimum amounts of chemicals.

Heterogeneous catalysts have been identified as a potential solution for problems associated with the homogeneous catalyst $\mathrm{NaOH}$. This is because, separation of the solid catalyst is easier, generation 
of wastewater is low, and reusing the catalyst is feasible. Calcium oxide, $\mathrm{CaO}$, has been used as a heterogeneous catalyst with many vegetable oils because unlike $\mathrm{NaOH}$ it is not corrosive, cheaper and non-toxic (Granados et al., 2010; Alba Rubio et al., 2012., Lee et al., 2015; Kesic et al., 2016). The spent catalyst has been successfully reused to prepare biodiesel for up to 20 times (Sharma et al., 2011). It is reported that when $\mathrm{CaO}$ is used as the catalyst for the transesterification of soyabean oil, the active catalyst is not $\mathrm{CaO}$, but calcium diglyceroxide which has formed on the surface of $\mathrm{CaO}$ due to the reaction of $\mathrm{CaO}$ with the by-product glycerol (Granados et al., 2010; Kouzu et al., 2008; Laura et al., 2013). Therefore, the direct use of calcium diglyceroxide for transesterifiction of soyabean oil has been studied and a yield of $85 \%$ has been obtained in $4 \mathrm{hr}$ of reaction period (Kouzu et al., 2010). The direct use of calcium diglyceroxide for the transesterifiction of sunflower oil has given $88 \%$ yield in $3 \mathrm{hr}$ of reaction period (Laura et al., 2013). Laura et al. (2013) have reported that the catalytic activity of calcium diglyceroxide is much higher than that of $\mathrm{CaO}$. The reason for the higher activity has been explained by Sanchez-Cantu et al. (2014) as follows. When calcium diglyceroxide crystal structure is interrupted at the surface, non-protonated basic oxygen anions get exposed. These anions are very reactive and they easily abstract a hydrogen atom from methanol and form $\mathrm{MeO}^{-}$. These nucleophilic $\mathrm{MeO}^{-}$attack carbonyl groups in the triglyceride molecule and form methyl esters of fatty acids and glycerol. Another advantage reported about calcium diglyceroxide over $\mathrm{CaO}$ is, unlike $\mathrm{CaO}$, the yield of biodiesel is not affected due to the exposure of calcium diglyceroxide to air (Kouzu et al., 2008; 2009). According to many reports in the literature, the mass transfer resistance controls the overall rate of methanolysis. Lukić et al. (2016) have reported that they have not observed it with calcium diglyceroxide. The reason given by them is that calcium diglyceroxide is adsorbed at the droplet interfaces between methanol and oil leading to the formation of fine dispersion of the two immiscible liquids. It has been reported by Kouzu et al. $(2008$; 2009) that when calcium diglyceroxide is used as the catalyst, the active catalyst is calcium alkoxide, which has formed during the refluxing of calcium diglyceroxide with methanol (Kouzu et al., 2010). The exact chemical formula of this alkoxide is not yet reported and the estimated formula is $\mathrm{CH}_{3} \mathrm{O}-\mathrm{Ca}-\mathrm{O}(\mathrm{OH})_{2} \mathrm{C}_{3} \mathrm{H}_{5}$. Calcium diglyceroxide has been successfully recycled five times in the transesterification process and the performance of calcium glycerolate has also been investigated (Reyero et al., 2014). All the above findings suggest that calcium diglyceroxide is a good heterogeneous catalyst for the production of biodiesel.
A major problem reported about the use of calcium-based heterogeneous catalysts is, contamination of biodiesel due to the leaching of $\mathrm{Ca}^{2+}$ ions from the catalyst into biodiesel (Alba Rubio et al., 2011; Sanchez-Cantu et al., 2014). When $\mathrm{Ca}^{2+}, \mathrm{Mg}^{2+}, \mathrm{Na}^{+}$and $\mathrm{K}^{+}$are present in biodiesel, they can form deposits which catalyse undesired side reactions and also can affect the poison emission control equipment in vehicles (Biodiesel Handling and Use Guide, 2008). Therefore international standard levels are given for presence of those ions in biodiesel. Although it is necessary to maintain the $\mathrm{Ca}^{2+}$ level in biodiesel, when $\mathrm{CaO}$ was used as the catalyst, most of the researchers have not given attention to determine the $\mathrm{Ca}^{2+}$ level in biodiesel. The contamination of biodiesel due to the leaching of $\mathrm{Ca}^{2+}$ ions from the catalyst $\mathrm{CaO}$ has been determined and steps have been introduced to decrease it by Alba Rubio et al. (2012) by precipitating $\mathrm{Ca}^{2+}$ ions using $\mathrm{Na}_{2} \mathrm{CO}_{3}$ as the precipitating agent. They have incorporated $\mathrm{Na}_{2} \mathrm{CO}_{3}$ to the transestrification mixture of sunflower oil. In addition to that, filtration and additional washings have been used to lower the $\mathrm{Ca}^{2+}$ and $\mathrm{Na}^{+}$levels further in order to maintain the recommended levels by ASTM D 6751. Although Alba Rubio et al. (2012) have given attention to maintain the $\mathrm{Ca}^{2+}$ and $\mathrm{Na}^{+}$levels in biodiesel, they have not given attention to minimise the amounts of chemicals used. The oil: methanol ratio used by them is very high (1:30). Amount of $\mathrm{Na}_{2} \mathrm{CO}_{3}$ used is also high. Also they have not used solid calcium diglyceroxide directly, instead they have used a slurry which consists of $\mathrm{CaO}$, methanol and glycerol resulting in the usage of high amounts of chemicals. In order to reduce the cost of production of biodiesel in the method reported by Alba Rubio et al. (2012), the direct use of calcium diglyceroxide and use of minimum amounts of chemicals giving the highest yield are necessary.

In certain Asian countries, biodiesel is commercially produced from palm oil using $\mathrm{NaOH}$ as the homogeneous catalyst. Although heterogeneous catalysis for biodiesel production is an environmental-friendly method, only a few reports are available on the use of heterogeneous catalysts for transesterification of palm oil. Some of these methods have given low yields and they have used high amounts of methanol and the catalyst (Boey et al., 2009; Chen et al., 2015; Chantara-Arpornchai et al., 2012). Although calcium diglyceroxide has been identified as a good catalyst for the production of biodiesel, no reports are available on the use of that catalyst in the production of biodiesel from palm olein oil.

Yield of biodiesel and the use of minimum amounts of chemicals giving the highest yield are two major economic parameters affecting production of biodiesel. Use of an environmentalfriendly method is also important. Therefore the 
objective of the present research was to develop a green, efficient method to produce biodiesel from palm olein oil by replacing $\mathrm{NaOH}$ with the greener heterogeneous catalyst calcium diglyceroxide while maintaining the $\mathrm{Ca}^{2+}$ and $\mathrm{Na}^{+}$levels and certain fuel qualities of biodiesel according to the recommended levels by ASTM and determine the minimum amounts of chemicals giving the maximum yield of biodiesel.

\section{MATERIALS AND METHODS}

\section{Materials}

Palm olein oil (commercial Turkey Brand), methanol (99.5\%, Fisher), glycerol (98\%, BDH), $\mathrm{CaO}$ $(\mathrm{BDH}), \mathrm{NaOH}(95 \%, \mathrm{MERCK})$ and $\mathrm{Na}_{2} \mathrm{CO}_{3}(99.5 \%$, Otto) were used. Methanol was dried and distilled before use. Palm olein was dried at $110^{\circ} \mathrm{C}$ for $1 \mathrm{hr}$. before use.

\section{Equipment}

Fatty acid methyl ester (FAME) composition of biodiesel was determined by using a Varian GC CP 3800 gas chromatograph (GC) equipped with a flame ionisation detector and a RTX 2330 Column. Initial temperature was $80^{\circ} \mathrm{C}$ and after an isothermal period of $4 \mathrm{~min}$. The GC oven was heated at $3^{\circ} \mathrm{C} /$ min to $230^{\circ} \mathrm{C}$ and held for $40 \mathrm{~min}$ and total time was $94 \mathrm{~min}$. Nitrogen was used as the carrier gas at a flow rate of $1 \mathrm{ml} \mathrm{min}^{-1}$. The split ratio was 50:1. The injector temperature and detector temperatures were $220^{\circ} \mathrm{C}$ and $240^{\circ} \mathrm{C}$ respectively.

Flash point and kinematic viscosity of biodiesel were obtained by GALLENKAMP Auto FlashPensky-Martens Closed Tester and E270 viscometer respectively. Calcium and sodium levels in biodiesel prepared by Method-2 were determined by using Thermoscientific atomic absorption spectrometer ICE $3000 \mathrm{AA} 05121002 \mathrm{v} 130$. The flame used was $\mathrm{N}_{2} \mathrm{O}-\mathrm{C}_{2} \mathrm{H}_{2}$ and the wave lengths used were $422.7 \mathrm{~nm}$ and $589 \mathrm{~nm}$ respectively.

Scanning electron microscopy (SEM) observations and FT-IR spectrum of the catalyst were obtained using a Hitachi SU 6600 microscope operating at $15.0 \mathrm{kV}$ and HITACHI 270-50 infrared spectrophotometer respectively.

\section{Methods}

All the experiments were carried out in triplicate. The yield of biodiesel was calculated using the following formula.

$$
\text { Yield }(\%)=\frac{(\text { weight } \text { of biodiesel } \times 100)}{\text { weight of raw oil }}
$$

Preparation of the catalyst, calcium diglyceroxide. The method reported by Mori et al. (2011) was slightly modified. Calcium oxide $(2.80 \mathrm{~g})$, methanol $(100 \mathrm{ml})$ and glycerol $(20 \mathrm{ml})$ were refluxed at $60^{\circ} \mathrm{C}$ for $2 \mathrm{hr}$. The product was filtered, washed with methanol and the residue was dried at $100^{\circ} \mathrm{C}$ for 1 $\mathrm{hr}$. Then it was ground, and sieved $(200 \mu \mathrm{m})$.

Determination of acid value of palm olein oil. Titrimetric method was used.

Preparation of Biodiesel. The following two methods were studied.

\section{a. Method-1.}

Calcium diglyceroxide (1.5 wt \% of palm oil) was added into methanol (1:6 molar ratio) and was stirred for $15 \mathrm{~min}$ at $1000 \mathrm{rpm}$. Pre-heated palm olein $(80 \mathrm{ml})$ was added into it and refluxed at $60^{\circ} \mathrm{C}$ for $15 \mathrm{hr}$. The mixture was allowed to cool to room temperature, filtered, biodiesel layer was separated from glycerol and then excess methanol was removed. Biodiesel was washed with distilled water $\left(50^{\circ} \mathrm{C}\right)$ and separated the biodiesel layer, centrifuged to remove any remaining catalyst and heated at $110^{\circ} \mathrm{C}$ for $1 \mathrm{hr}$. The calcium level of biodiesel was determined. White flakes were formed in biodiesel when stored in a sealed vial for three to four days.

\section{b. Method-2.}

In Method-1, reaction period was too long (15 hr) and therefore to increase the reaction rate, refluxing temperature was increased in Method- 2 to $65^{\circ} \mathrm{C}$. As white flakes were formed in Method-1, amount of calcium diglyceroxide used was reduced to 1.0 (wt $\%$ of oil) in Method-2.

Calcium diglyceroxide (1.0 wt \% of oil) was stirred with methanol (1:6 molar ratio) for $15 \mathrm{~min}$ at $1000 \mathrm{rpm}$. Anhydrous $\mathrm{Na}_{2} \mathrm{CO}_{3}$ (5 wt \% of oil) was added into it and stirring was continued for 5 min. Pre-heated palm olein $(80 \mathrm{ml})$ was added into it and refluxed at $65^{\circ} \mathrm{C}$ for $5 \mathrm{hr}$. The mixture was allowed to cool to room temperature, filtered and biodiesel layer was separated from glycerol and then excess methanol was removed. Biodiesel was then washed with distilled water $\left(50^{\circ} \mathrm{C}\right)$ and separated the biodiesel layer, centrifuged to remove any remaining catalyst, heated at $110^{\circ} \mathrm{C}$ for $1 \mathrm{hr}$ and stored in a vial. White flakes were not formed in biodiesel when stored in a sealed vial.

Further purification of biodiesel prepared by Method-2. Sodium level of the biodiesel prepared by Method-2 was determined and it was very close to the recommended level by ASTM. Therefore biodiesel was further purified by washing with hot $\left(50^{\circ} \mathrm{C}\right)$ distilled water until the aqueous layer 
becomes clear. Then biodiesel layer was separated and heated at $110^{\circ} \mathrm{C}$ for $1 \mathrm{hr}$. Sodium and calcium levels in biodiesel were determined and both agreed with the recommended levels. The yield, $\mathrm{pH}$ and acid value of biodiesel were $83 \%, 7$ and $0.25 \mathrm{mg}$ $\mathrm{KOH} \mathrm{g}^{-1}$ respectively.

\section{Determination of Optimum Conditions}

The above procedure was repeated for a refluxing period of $3 \mathrm{hr}$. The yield was the same for a refluxing periods of 3 and $5 \mathrm{hr}$ and therefore $3 \mathrm{hr}$ was considered as the best reaction period. After optimising the reaction period, transesterification was repeated with different ratios of oil:methanol (molar ratios of 1:5, 1:6, 1:9, 1:12, 1:14) and a refluxing period of $3 \mathrm{hr}$, while keeping the other parameters in the Method-2 constant. The oil:methanol ratio giving the highest yield was 1:6. After optimising the reaction period and oil:methanol ratio, above procedure was repeated for different amounts of the catalyst $(0.05 \%, 0.1 \%, 0.2 \%, 0.5 \%, 1 \% \mathrm{w} / \mathrm{w}$ oil $)$, by keeping the oil: methanol ratio constant (1:6) and reaction period of $3 \mathrm{hr}$. The amount of the catalyst giving the highest yield was $0.2 \%$. After optimising the reaction period, oil:methanol ratio and the amount of the catalyst, amount of $\mathrm{Na}_{2} \mathrm{CO}_{3}$ was optimised by repeating the above experiment using oil:methanol (1:6), catalyst $(0.2 \%)$ and reaction period of $3 \mathrm{hr}$ for different amounts of $\mathrm{Na}_{2} \mathrm{CO}_{3}(1 \%$, $2.5 \%, 5 \%$ w w oil). Optimum amount of $\mathrm{Na}_{2} \mathrm{CO}_{3}$ was $2.5 \%$. Biodiesel was then prepared under the above mentioned optimum conditions (reaction period $3 \mathrm{hr}$, oil:methanol 1:6, catalyst $0.2 \%$ and $\mathrm{Na}_{2} \mathrm{CO}_{3}$ $2.5 \%$ ) and the yield was $92.2 \%$.

Preparation of biodiesel using the previously used catalyst. The catalyst used once for the transesterification process was separated from the reaction mixture, washed with methanol and dried at $110^{\circ} \mathrm{C}$ for $2 \mathrm{hr}$. By using that catalyst, biodiesel was prepared under the optimum conditions and the yield was determined. Again the catalyst was separated, washed and dried as described above and repeated the transesterification process and the yield was determined.

Characterisation of the catalyst and the used catalyst. The catalyst was characterised by Fourier transform infra-red (FT-IR) spectroscopy and scanning electron microscopy. The FT-IR spectrum of the fresh catalyst was compared with the FTIR spectrum reported for calcium diglyceroxide by Lukić et al. (2016). The catalyst used once for the transesterification process was washed with methanol, dried at $110^{\circ} \mathrm{C}$ and the FT-IR spectrum was taken. It was compared with the FT-IR of the fresh catalyst.
Determination of $\mathrm{Ca}^{2+}$ and $\mathrm{Na}^{+}$concentrations in biodiesel. The $\mathrm{Ca}^{2+}$ and $\mathrm{Na}^{+}$concentrations in aqueous extracts of biodiesel samples obtained without further purification step and after further purification step of the Method-2 were determined by atomic absorption spectroscopy (Basilio et al., 2012). The $\mathrm{Ca}^{2+}$ level in the aqueous extract of biodiesel prepared by Method-1 was determined by titrating with EDTA, using murexide as the indicator. Titrimetric method was used for biodiesel prepared by Method-1, because the calcium level in it is high.

Determination of quality of biodiesel prepared by Method-2. Density at $15^{\circ} \mathrm{C}$ and $\mathrm{pH}$ were determined by ASTM D1298 and $\mathrm{pH}$ meter respectively. Cloud point, pour point, kinematic viscosity and flash point were determined by ASTM D2700, ASTM D97, ASTM D445 and ASTM D93. Acid number of biodiesel was determined by titrating $1.0000 \mathrm{~g}$ of biodiesel in toluene $(50 \% \mathrm{v} / \mathrm{v})$, water $(0.5 \% \mathrm{v} / \mathrm{v})$ and isopropyl alcohol $(49.5 \% \mathrm{v} / \mathrm{v})$ with $0.1 \mathrm{M}$ $\mathrm{KOH}$ in isopropyl alcohol using phenolphthalein as the indicator. Fatty acid methyl ester (FAME) composition of biodiesel was determined by GC analysis.

\section{RESULTS AND DISCUSSION}

\section{The Best Method to Prepare Biodiesel Out of the Two Methods Studied}

The transesterification reaction mixture is a three-phase system. In Method-1, refluxing temperature used was $60^{\circ} \mathrm{C}$. Since the temperature was low, mixing of the three phases is slow and as a result, the glycerol layer was slowly appeared and it took about $15 \mathrm{hr}$ of refluxing period to appear a clearly visible glycerol layer. If temperature is increased, mixing will be increased. Therefore in Method-2, the temperature was increased to $65^{\circ} \mathrm{C}$ and gradual formation of the glycerol layer was seen during refluxing and it was clearly visible in 3 $\mathrm{hr}$ of refluxing period. Refluxing was continued for another $2 \mathrm{hr}$.

The recommended level for $\mathrm{Ca}^{2+}$ in biodiesel by ASTM D 6751 is $<5$ ppm and the $\mathrm{Ca}^{2+}$ level in biodiesel prepared by Method-1 was 1252 ppm which is very much higher than the recommended level. Alba Rubio et al. (2012) have reported that longer refluxing period results an increase in the calcium content in biodiesel. The refluxing period used in Method-1 in the present study was $15 \mathrm{hr}$ and this could be one reason for showing a high level of calcium in biodiesel. Formation of flakes was observed when biodiesel was kept in a sealed vial for three to four days. Therefore, Method-1 was rejected. Alba Rubio et al. (2012) also have reported 
formation of such flakes in biodiesel, when $\mathrm{CaO}$ was used as the catalyst to prepare biodiesel from sunflower oil. They have analysed these white flakes by infrared (IR) and atomic absorption spectroscopy and confirmed that these white flakes are calcium soaps. They have further stated that because of the solubility, these calcium soaps get dissolved in biodiesel and can precipitate after a period of ageing. Considering their findings, it was assumed that the white flakes formed in Method-1 in the present study are also calcium soaps. Alba Rubio et al. (2012) have ruled out the possibility of neutralisation of free fatty acids (FFA) because FFA content in sunflower oil used has been low. They have suggested that white flakes are formed due to saponification of glycerides and FAME and it has happened simultaneously during the transeserification catalysed by $\mathrm{CaO}$. The FFA content of palm olein oil used in the present study was also low $\left(0.25 \mathrm{mg} \mathrm{KOH} \mathrm{g}^{-1}\right)$ and formation of white flakes in the present study also could be due to the above reason.

To control the contamination of biodiesel by $\mathrm{Ca}^{2+}$ ions, Alba Rubio et al. (2012) have used $\mathrm{Na}_{2} \mathrm{CO}_{3}$ as a precipitating agent. Rinsing of biodiesel with $\mathrm{Na}_{2} \mathrm{CO}_{3}$ in boiling methanol is one method they have used. The other method they have used is incorporating $\mathrm{Na}_{2} \mathrm{CO}_{3}$ into the transesterification reaction mixture. Both methods have maintained the $\mathrm{Ca}^{2+}$ and $\mathrm{Na}^{+}$levels $<5 \mathrm{ppm}$. Due to the formation of white flakes in the biodiesel prepared by Method-1 in the present study, in Method-2 amount of calcium diglyceroxide used was reduced to $1.0 \%$ and $\mathrm{Na}_{2} \mathrm{CO}_{3}$ was incorporated as the precipitating agent into the transesterification reaction mixture. Flakes were not formed in biodiesel prepared by this method, when stored even up to six months. The $\mathrm{Na}^{+}$level in biodiesel obtained by Method-2 was $4.8 \mathrm{ppm}$ and it is very close to the recommended maximum level of $5 \mathrm{ppm}$. Therefore further purification by an additional washing step with hot water was introduced and it successfully lowered the sodium level to $0.3 \mathrm{ppm}$ (Figure 1). The $\mathrm{Ca}^{2+}$ level was $2 \mathrm{ppm}$ and it also agrees with the recommended level by ASTM D 6751. Therefore, the additional purification step was included when determining the best reaction conditions. Another possible reason for

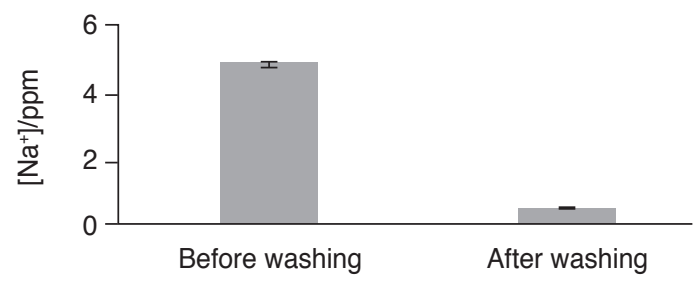

Figure 1. Effect of additional washing step with hot water on $\mathrm{Na}^{+}$level. Reaction conditions: molar ratio oil: $\mathrm{MeOH}, 1: 6$; catalyst, $0.2 \%$ (w/w) of oil; $\mathrm{Na}_{2} \mathrm{CO}_{3}, 2.5 \%$ (w/w) of oil; reaction period, $3 \mathrm{hr}$; temperature, $65^{\circ} \mathrm{C}$. low level of calcium in the biodiesel prepared by Method- 2 could be shorter $(3 \mathrm{hr}$ ) refluxing period.

\section{Best Reaction Conditions}

In order to reduce the cost of production of biodiesel, best reaction conditions were determined.

Effect of reaction period on the yield of biodiesel. Glycerol is the by-product of the transesterification reaction. Formation of the glycerol layer was observed with the increase in the reaction period. Figure 2 shows that the yields of biodiesel in $3 \mathrm{hr}$ and 5 $\mathrm{hr}$ of reaction periods are the same $(92 \%)$. Therefore, out of the studied reaction periods $3 \mathrm{hr}$ was selected and was used for all the other experiments.

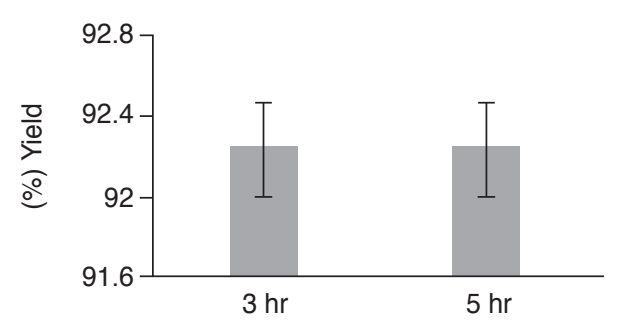

Figure 2. Effect of reaction period on \% yield. Reaction conditions: molar ratio oil:methanol, 1:12; catalyst, $0.5 \%$ (w/w) of oil; $\mathrm{Na}_{2} \mathrm{CO}_{3}$, $5 \%(w / w)$ of oil; temperature, $65^{\circ} \mathrm{C}$.

When calcium diglyceroxide has been used as the catalyst, the optimum reaction period reported for transesterifiction of soyabean oil (Kouzu et al., 2010) and for sunflower oil (Alba Rubio et al., 2012) are $3 \mathrm{hr}$ and $5 \mathrm{hr}$ respectively. This suggests that the present method is more efficient than the method reported by Alba Rubio et al. (2012). Reaction period reported by Sanchez-Cantu et al. (2014) is $2 \mathrm{hr}$ for castor oil. The lesser time required for their study than in the present study may be due to the very high amount of methanol used by them (1:37 molar ratio based on molecular weight of castor oil as 896) which facilitate mixing of phases.

Effect of oil:methanol ratio on the yield of biodiesel. Under the optimum reaction period, the effect of oil:methanol ratio on the yield of biodiesel is shown in the Figure 3.

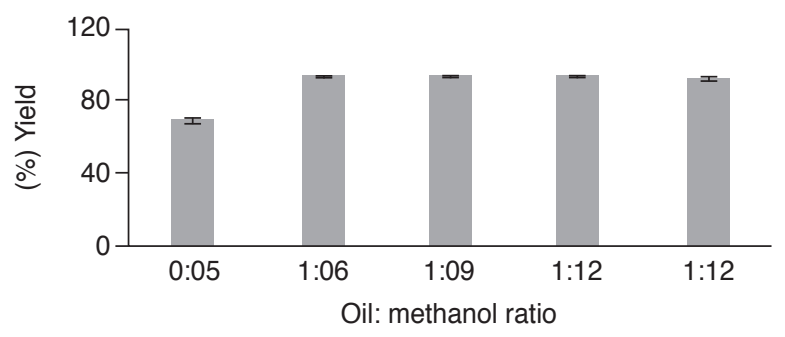

Figure 3. Effect of oil:methanol ratio on \% yield. Reaction conditions: catalyst, $0.5 \%$ (w/w) of oil; $\mathrm{Na}_{2} \mathrm{CO}_{3}, 5 \%$ (w/w) of oil; reaction period, $3 \mathrm{hr}$; temperature, $65^{\circ} \mathrm{C}$. 
Transesterification is a reversible process and the stoichiometry of triglyceride:methanol is 1:3.

\begin{tabular}{|c|c|c|c|c|c|}
\hline $\mathrm{R}_{1} \mathrm{COOCH}_{2}$ & & & $\mathrm{HOCH}_{2}$ & & $\mathrm{R}_{1} \mathrm{COOCH}_{3}$ \\
\hline $\mathrm{R}_{2} \mathrm{COOCH}$ & $+3 \mathrm{CH}_{3} \mathrm{OH}$ & Catalyst & $\mathrm{HOCH}$ & + & $\begin{array}{l}+ \\
\mathrm{R}_{2} \mathrm{COOCH}_{3} \\
+\end{array}$ \\
\hline $\mathrm{R}_{3} \mathrm{COOCH}_{2}$ & Methanol & & $\mathrm{HOCH}_{2}$ & + & $\mathrm{R}_{3} \mathrm{COOCH}_{3}$ \\
\hline Triglyceride & & & Glycerol & & $\begin{array}{l}\text { Mixture of alky1 } \\
\text { ester (biodiesel) }\end{array}$ \\
\hline
\end{tabular}

According to the above equation, excess methanol is expected to shift the equilibrium towards formation of biodiesel. In parallel with that, in this study when oil:methanol ratio was increased from 1:5 to 1:6, the yield of biodiesel increased from $72 \%$ to $92 \%$. When it was increased further, there was no change in the yield (Figure 3) and therefore 1:6 ratio was selected as the optimum ratio. The oil:methanol ratio used by Alba Rubio et al. (2012) and Laura et al. (2013) for sunflower oil and Kouzu et al. (2010) for soyabean oil are 1:30, 1:14 and 1:12 respectively and those amounts are two to five times higher than the amount used in the present study. Therefore the present method reduces the cost of production of bioiesel.

Effect of amount of the catalyst on the yield of biodiesel. The optimum reaction period of $3 \mathrm{hr}$ and oil: methanol ratio of 1:6 was used to determine the effect of amount of the catalyst and the results are shown in the Figure 4.

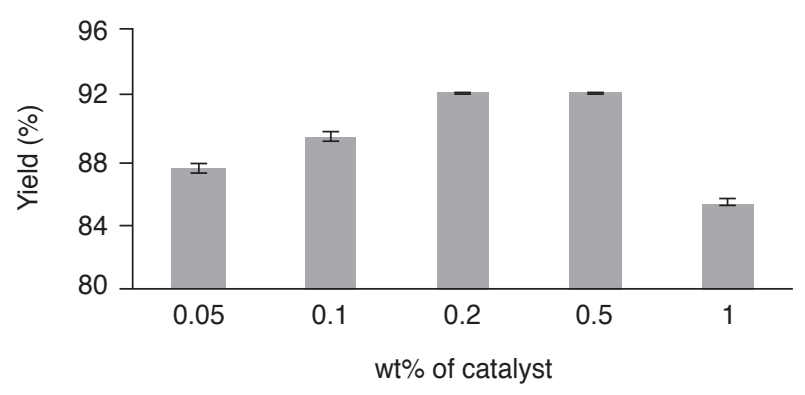

Figure 4. Effect of amount of the catalyst calcium diglyceroxide on $\%$ yield. Reaction conditions: molar ratio oil: methanol, 1:6; $\mathrm{Na}_{2} \mathrm{CO}_{3}, 5 \%$ $(w / w)$ of oil ; reaction period, $3 \mathrm{hr}$; temperature, $65^{\circ} \mathrm{C}$.

With increase in the amount of the catalyst from $0.05 \%$ to $0.2 \%$, the yield increased from $87 \%$ to $93 \%$. A possible reason is that with increase in the amount of the catalyst, available active sites increases. The yield of biodiesel was the same with $0.2 \%$ and $0.5 \%$ of the catalyst, but when the amount of the catalyst was increased to $1 \%$, the yield decreased to $83 \%$. This decrease could be due to low mixing of reactants in the presence of too much of the catalyst. According to Figure 4, the optimum amount of the catalyst required was considered as $0.2 \%$. The amount of calcium diglyceroxide used for transesterification of soyabean oil by Kouzu et al. (2010) and for sunflower oil by Laura et al. (2013) are $0.4 \%$ and $0.7 \%$ respectively and these amounts are twice or thrice higher than the amount used in the present study. Therefore, due to the lower amount of calcium glyceroxide used in the present study, leaching of $\mathrm{Ca}^{2+}$ ions from the catalyst and production cost of biodiesel would be lesser than their method.

Effect of amount of $\mathrm{Na}_{2} \mathrm{CO}_{3}$ on the yield of biodiesel. The optimum reaction period of $3 \mathrm{hr}$, oil:methanol ratio of $1: 6$ and $0.2 \%$ of the catalyst were used to determine the effect of amount of $\mathrm{Na}_{2} \mathrm{CO}_{3}$ on the yield of biodiesel. Figure 5 shows that the minimum amount of $\mathrm{Na}_{2} \mathrm{CO}_{3}$ required to obtain the highest yield $(92.2 \%)$ is $2.5 \%$. Laura et al. (2013) and Kouzu et al. (2010) also have used calcium diglyceroxide as the catalyst, but have not determined the $\mathrm{Ca}^{2+}$ level in biodiesel and have not used any method to remove $\mathrm{Ca}^{2+}$ ions from biodiesel. Alba Rubio et al. (2012) have used $\mathrm{CaO}$ as the catalyst and $5 \% \mathrm{Na}_{2} \mathrm{CO}_{3}$ to remove $\mathrm{Ca}^{2+}$ ions by precipitation. Due to the amount of $\mathrm{Na}_{2} \mathrm{CO}_{3}$ used in the present study is less than half of the amount used by Alba Rubio et al. (2012), contamination of biodiesel due to $\mathrm{Na}^{+}$ions should be lesser and cost of production of biodiesel also lower.

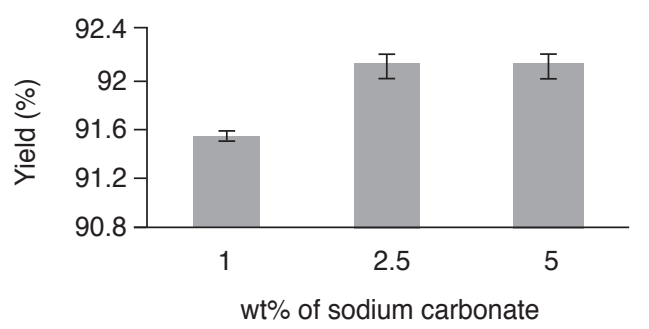

Figure 5. Effect of amount of $\mathrm{Na}_{2} \mathrm{CO}_{3}$ on \% yield. Reaction conditions: molar ratio oil: $\mathrm{MeOH}, 1: 6$; catalyst, $0.2 \%(w / w)$ of oil; reaction period, $3 \mathrm{hr}$; temperature, $65^{\circ} \mathrm{C}$.

Comparison of the present method with reported methods. Present method is compared with certain reported methods (Table 1).

According to Table 1, Deshpande and Kulkarni (2012) have used the homogeneous catalyst $\mathrm{NaOH}$ which is corrosive, but all the others have used greener non-corrosive heterogeneous catalysts. Although it is necessary to determine the calcium and sodium levels in biodiesel and compare with ASTM recommended levels, in Table 1 only Alba Rubio et al. (2012) and the present work have done it and in both, those levels have agreed with the recommended levels. Amount of methanol used by Alba Rubio et al., is five times greater than in the present study and the amount of $\mathrm{Na}_{2} \mathrm{CO}_{3}$ used is twice than that of in the present study. Therefore, the cost of production of biodiesel in the present study 


\begin{tabular}{|c|c|c|c|c|c|c|c|}
\hline \multirow[b]{2}{*}{$\begin{array}{l}\text { Item used for } \\
\text { comparison }\end{array}$} & \multirow[b]{2}{*}{$\begin{array}{l}\text { Present } \\
\text { study }\end{array}$} & \multicolumn{5}{|c|}{ Reported methods } & \multirow[b]{2}{*}{$\begin{array}{l}\text { Alba Rubio } \\
\text { et al. } \\
(2012)\end{array}$} \\
\hline & & $\begin{array}{l}\text { Deshpande } \\
\text { and } \\
\text { Kulkami } \\
(2012)\end{array}$ & $\begin{array}{l}\text { Chen } \\
\text { et al. } \\
(2015)\end{array}$ & $\begin{array}{l}\text { Kouza } \\
\text { et al. } \\
(2010)\end{array}$ & $\begin{array}{l}\text { Laura } \\
\text { et al. } \\
(2013)\end{array}$ & $\begin{array}{l}\text { Sanchez- } \\
\text { Cantu } \\
\text { et al. } \\
(2014)\end{array}$ & \\
\hline Oil & $\begin{array}{l}\text { Palm } \\
\text { olein }\end{array}$ & $\begin{array}{l}\text { Palm } \\
\text { kernel }\end{array}$ & Palm & $\begin{array}{l}\text { Soya- } \\
\text { bean }\end{array}$ & $\begin{array}{l}\text { Sun- } \\
\text { flower }\end{array}$ & Castor & $\begin{array}{l}\text { Sun- } \\
\text { flower }\end{array}$ \\
\hline $\begin{array}{l}\text { Homogeneous } \\
\text { catalyst }\end{array}$ & No & $\mathrm{NaOH}$ & No & No & No & No & No \\
\hline $\begin{array}{l}\text { Heterogeneous } \\
\text { catalyst }\end{array}$ & * & No & $\begin{array}{l}\text { Calcined rice } \\
\text { egg shell } \\
\text { loaded with } \\
\text { husk ash }\end{array}$ & * & * & * & $* *$ \\
\hline Alcohol used & Methanol & Ethanol & Methanol & Methanol & Methanol & Methanol & Methanol \\
\hline $\begin{array}{l}\text { Oil: alcohol } \\
\text { molar ratio }\end{array}$ & $1: 6$ & $1: 6$ & $1: 9$ & $1: 12$ & $1: 14$ & $1: 37$ & $1: 30$ \\
\hline $\begin{array}{l}\text { Amount of the } \\
\text { catalyst used } \\
(\mathrm{w} / \mathrm{w} \%)\end{array}$ & 0.2 & 1 & 7 & 0.4 & 0.7 & 1.5 & 0.2 \\
\hline $\begin{array}{l}\text { Amount of } \\
\mathrm{Na}_{2} \mathrm{CO}_{3} \text { used } \\
(\mathrm{w} / \mathrm{w} \%)\end{array}$ & 2.5 & No & - & - & - & - & 5 \\
\hline $\begin{array}{l}\text { Reaction } \\
\text { period }(\mathrm{hr})\end{array}$ & 3 & 1 & 4 & 3 & 3 & 2 & 5 \\
\hline Yield (\%) & 92.2 & 95.8 & 91.5 & 87 & 88 & 100 & 92 \\
\hline $\begin{array}{l}\mathrm{Na}^{+} \text {and } \mathrm{Ca}^{2+} \\
\text { levels in } \\
\text { biodiesel (ppm) }\end{array}$ & $\begin{array}{l}\mathrm{Na}^{+} 0.3 \\
\mathrm{Ca}^{2+} 2\end{array}$ & Not reported & Not reported & Not reported & Not reported & Not reported & $<5$ \\
\hline $\begin{array}{l}\text { Whether the } \\
\text { catalyst is } \\
\text { corrosive }\end{array}$ & No & Yes & No & No & No & No & No \\
\hline
\end{tabular}

Note: *Calcium diglyceroxide.

**Slurry of $\mathrm{CaO}$, methanol and glycerol.

is very much cheaper than the method reported by Alba Rubio et al. (2012).

\section{Characterisation of the Fresh Catalyst and the Used Catalyst}

FT-IR spectra. The FT-IR spectrum of the fresh catalyst showed (Figure 6) the presence of $\mathrm{v}_{\mathrm{O}-\mathrm{H}}(3650$ $\left.\mathrm{cm}^{-1}\right), v_{\mathrm{C}-\mathrm{H}}$ stretching $\left(2900,2880 \mathrm{~cm}^{-1}\right), v_{\mathrm{C}-\mathrm{H}}$ vibratons $(\approx 1490)$, and $v_{\mathrm{C}-\mathrm{O}}$ stretching $\left(1140,1085 \mathrm{~cm}^{-1}\right)$. Broad bands at $3160 \mathrm{~cm}^{-1}$ and $1700 \mathrm{~cm}^{-1}$ are due to water adsorbed on to the surface of the catalyst. The FTIR absorptions are in agreement with the FT-IR spectrum of calcium diglyceroxide reported by Lukić et al. (2016). This confirms that the catalyst prepared is calcium diglyceroxide. Based on the XRD data, Santez-Cantu et al. (2014) have reported that when calcium diglyceroxide is produced from hydrated lime and glycerine, $\mathrm{Ca}(\mathrm{OH})_{2}$ and $\mathrm{CaCO}_{3}$ are present in small amounts in the calcium diglyceroxide phase. However, the strong band at $1400 \mathrm{~cm}^{-1}$ which is characteristic for $\mathrm{CO}_{3}{ }^{2-}$ is absent in the FT-IR spectrum of calcium diglyceroxide prepared in the present study. Laura et al. (2013) also have not observed the presence of $\mathrm{CO}_{3}{ }^{2-}$ in the FT-IR spectrum of of calcium diglyceroxide. Due to lack of XRD facility in the present study, it was not possible to carry out XRD studies of the catalyst.

The FT-IR spectrum of the used catalyst in the present study (Figure 7) is different from that of the fresh catalyst. However, $v_{\mathrm{C}-\mathrm{H}}$ stretching $(2900,2880$ $\mathrm{cm}^{-1}$ ) are seen in the used catalyst also. The intense signal at $1450 \mathrm{~cm}^{-1}$ and the other two bands at 877 and $696 \mathrm{~cm}^{-1}$ show the presence of $\mathrm{CO}_{3}^{2-}$. This suggests that the used catalyst contains $\mathrm{CO}_{3}{ }^{2-}$ and it could be due to $\mathrm{Na}_{2} \mathrm{CO}_{3}$ used and $\mathrm{CaCO}_{3}$ precipitated. The IR spectrum of the used catalyst of $\mathrm{CaO}$ reported by Kouzu et al. (2010) indicates the presence of calcium alkoxide. But characteristic signals for alkoxide are absent in the IR spectrum of the used catalyst in the 
present study. Based on the work carried out in the present study, it was not possible to identify the chemical structure of the used catalyst.

SEM of the fresh catalyst. The SEM of calcium diglycerixide reported by Laura et al. (2013) has shown its typical tablet shape. SEM of the fresh catalyst in the present study did not show such tablet shape structures (Figure 8).

Preparation of biodiesel using the catalyst used previously. When transesterification of palm olein oil was carried out with the catalyst which has been used once or twice previously, the yield of biodiesel increased from $92.2 \%$ to $94.3 \%$ (Figure 9). As it was not possible to identify the chemical structure of the used catalyst, reason for above observation is not clear. By studying the transesterification of castor oil using calcium diglyceroxie as the catalyst, SanchezCantu et al. (2014) have reported that the stability of calcium diglyceroxide decreases when the oil is hygroscopic and acid value is high. This affects the reusability of the catalyst. This matter does not apply for palm olein oil because it is not hygroscopic as castor oil and the acid value was also low.

\section{Fuel Qualities of Biodiesel}

Certain fuel qualities of biodiesel prepared by Method-2 are compared in Table 2 with recommended values by ASTM D 6751 and with those reported for biodiesel from palm oil when $\mathrm{NaOH}$ has been used as the catalyst and also with petrodiesel. Except kinematic viscosity of biodiesel produced in the present study, all the other values agree with ASTM D 6751 levels. To solve the problem of high kinematic viscosity, biodiesel can be blended with petrodiesel. Cloud point is very close to the recommended value and it was $15.5^{\circ} \mathrm{C}$. It indicates that biodiesel is suitable to be used in tropical countries, but not suitable during winter in certain countries. The flash point of biodiesel was $176^{\circ} \mathrm{C}$, and it is greater than the minimum value given by ASTM D 6751. The high flash point indicates that the storage and transportation will be safe. The fuel qualities studied for biodiesel produced in the present work, except flash point and kinematic viscosity, are compatible with reported values for biodiesel produced from palm oil in the presence of the catalyst $\mathrm{NaOH}$

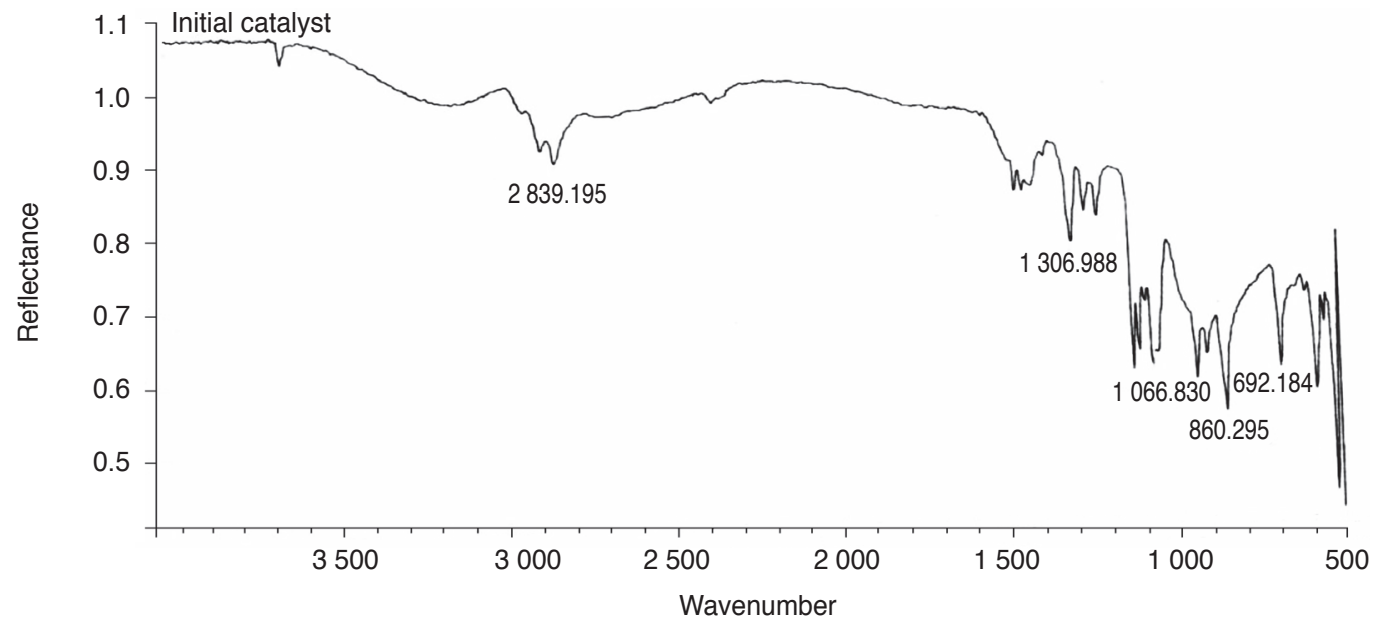

Figure 6. Fourier transform infra-red (FT-IR) spectrum of the fresh catalyst.

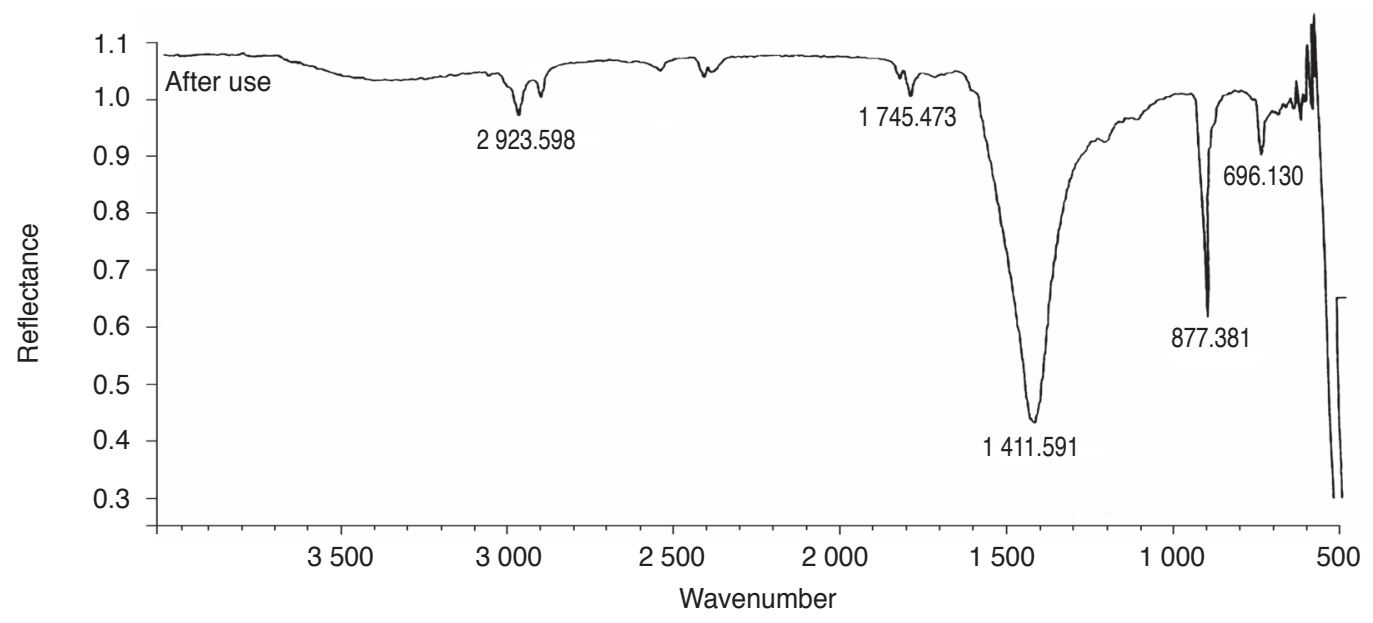

Figure 7. Fourier transform infra-red (FT-IR) spectrum of the catalyst used once. 


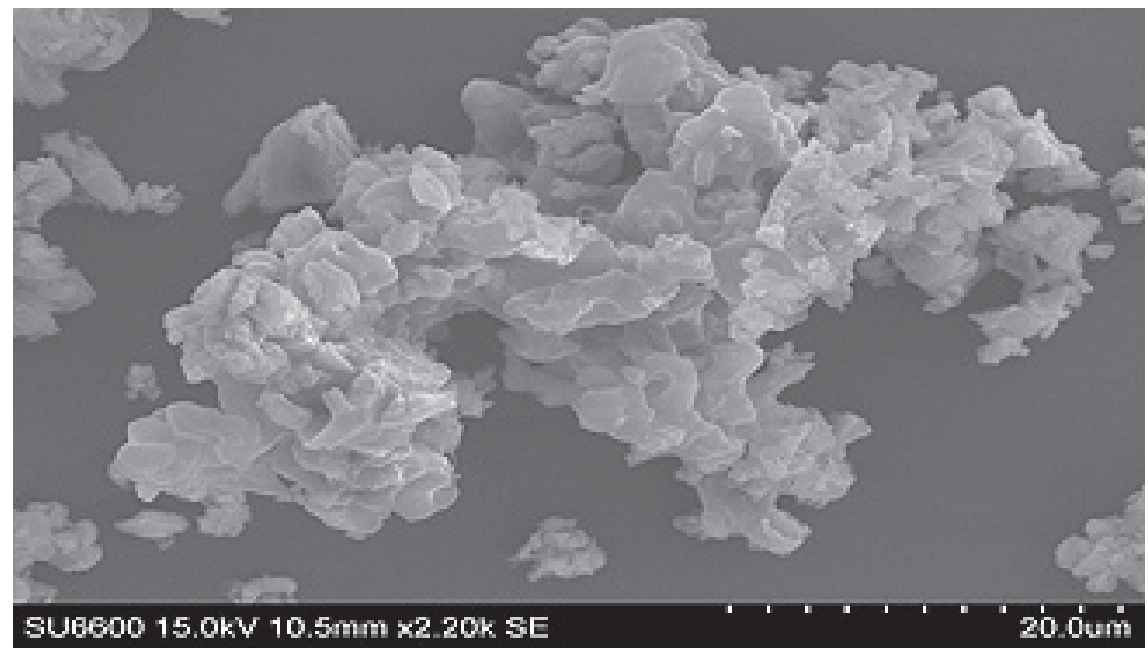

Figure 8. Scanning electron microscopy (SEM) of the fresh catalyst (magnification: $2.2 \mathrm{k}$ ).

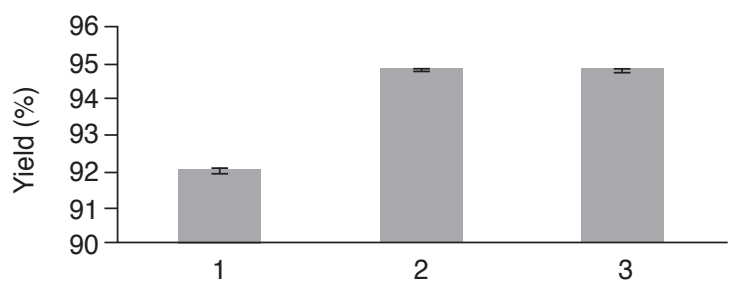

Note: 1 - Fresh catalyst; 2 - Catayst used once; 3 - Catalyst used twice.

Figure 9. Effect of fresh catalyst and the used catalyst on the \% yield. Reaction conditions: molar ratio oil: $\mathrm{MeOH}, 1: 6$; catalyst, $0.2 \%$ (w/w) of oil; reaction period, $3 \mathrm{hr}$; temperature, $65^{\circ} \mathrm{C}$.

\section{FAME Composition of Biodiesel}

Properties of biodiesel mainly depend on it's FAME composition. Major FAME composition of biodiesel observed in the GC and a comparison with reported values for biodiesel from certain other oils are given in the Table 3.

When the amount of polyunsaturated fatty acid methyl esters in biodiesel is high, oxidative stability will be low. Therefore, the presence of $15.78 \%$ of methyl linoleate (C18:3) is not good. On the other hand, emission of NOx is reduced with increase in unsaturation. Viscosity of biodiesel increases with increase in the chain length and degree of saturation and therefore the presence of total of $41.63 \%$ of saturated methyl palmitate $(\mathrm{C} 16: 0)$ and methyl stearate (C18:0) is not good. A fuel having high amount of mono-unsaturated methyl oleate $(18: 1)$ is good and this biodiesel has $36.86 \%$ of methyl oleate. Above values suggest that poor fuel qualities of biodiesel produced will be cancelled by good qualities.

\section{CONCLUSION}

Good quality biodiesel can be produced by the transesterification of palm olein oil using calcium diglyceroxide as the solid catalyst and $\mathrm{Na}_{2} \mathrm{CO}_{3}$ as the precipitating agent for $\mathrm{Ca}^{2+}$ ions. The amount of calcium diglyceroxide, $\mathrm{Na}_{2} \mathrm{CO}_{3}$ and oil:methanol ratio used in this new method are very much

TABLE 2. COMPARISON OF QUALITY OF BIODIESEL WITH ASTM D 6751 RECOMMENDED LEVELS AND REPORTED VALUES FOR BIODIESEL FROM PALM OIL (catalyst: $\mathrm{NaOH)}$ AND PETRODIESEL*

\begin{tabular}{|c|c|c|c|c|c|c|}
\hline $\begin{array}{l}\text { Diesel type \& } \\
\text { ASTM values }\end{array}$ & $\begin{array}{c}\mathrm{Ca}^{2+} \& \mathrm{Na}^{+} \\
\text {levels (ppm) }\end{array}$ & $\begin{array}{c}\text { Acid \# } \\
\left(\mathrm{mg} \mathrm{KOH} \mathrm{g}^{-1}\right)\end{array}$ & $\begin{array}{c}\text { Density at } \\
15^{\circ} \mathrm{C}\left(\mathrm{kg} \mathrm{m}^{-3}\right)\end{array}$ & $\begin{array}{c}\text { Flash point } \\
\left({ }^{\circ} \mathrm{C}\right)\end{array}$ & $\begin{array}{l}\text { Cloud point } \\
\left({ }^{\circ} \mathrm{C}\right)\end{array}$ & $\begin{array}{l}\text { Kinematic } \\
\text { viscosity } \\
\text { at } 40^{\circ} \mathrm{C}(\mathrm{cSt})\end{array}$ \\
\hline Present study* & $\begin{array}{l}\mathrm{Ca}^{2+} 2 \\
\mathrm{Na}^{+} 0.3\end{array}$ & 0.23 & 887.4 & $>176$ & 15.55 & 7.79 \\
\hline ASTM & $\begin{array}{l}\mathrm{Ca}^{2+}<5 \\
\mathrm{Na}^{+}<5\end{array}$ & $<0.8$ & $866-890$ & $>130$ & -3 to 15 & $1.8-6.0$ \\
\hline $\begin{array}{l}\text { From palm oil } \\
\quad(\text { catalyst-NaOH) })^{* *}\end{array}$ & -- & 0.27 & 866 & 140 & 12 & 4.1 \\
\hline Petrodiesel & -- & $<0.2$ & $820-860$ & 60 & -35 to 5 & $1.5-5.0$ \\
\hline
\end{tabular}

Note: *Reaction conditions: temperature, $65^{\circ} \mathrm{C}$; calcium diglyceroxide, $0.2 \%(\mathrm{w} / \mathrm{w})$ of oil; $\mathrm{Na}_{2} \mathrm{CO}_{3}, 2.5 \%$ (w/w) of oil; molar ratio oil:methanol, 1:6, reaction period $3 \mathrm{hr}$.

${ }^{* *}$ Deshpande and Kulkarni (2012). 
TABLE 3. COMPARISON OF FATTY ACID METHYL ESTER (FAME) COMPOSITION OF BIODIESEL WITH REPORTED VALUES FOR BIODIESEL FROM CERTAIN OTHER OILS

\begin{tabular}{lccccc}
\hline Major FAME & $\begin{array}{c}\text { Present study } \\
(\boldsymbol{\%})\end{array}$ & $\begin{array}{c}\text { Crude palm oil } \\
\mathbf{( \% )}\end{array}$ & $\begin{array}{c}\text { Palm stearin }^{*} \\
\mathbf{( \% )}\end{array}$ & $\begin{array}{c}\text { Sunflower oil }^{* *} \\
\mathbf{( \% )}\end{array}$ & $\begin{array}{c}\text { Jatropa oil }^{* * *} \\
(\boldsymbol{\%})\end{array}$ \\
\hline Methyl palmitate (16:0) & 38.23 & 44.3 & 52.0 & 3.82 & 15.6 \\
Methyl stearate (18:0) & 3.43 & 5 & 4.1 & 6.25 & 9.7 \\
Methyl oleate (18:1) & 36.86 & 39.1 & 32.7 & 69.12 & 40.8 \\
Methyl linoleate (18:2) & 15.78 & 10.1 & 7.9 & 17.04 & 32.1 \\
\hline
\end{tabular}

Note: * Alamu et al. (2008); **Sagiroglu et al. (2011); ${ }^{* * *}$ Maya et al. (2005).

lower than the amounts reported by previous researchers for other oils. Therefore this method can be considered as a novel environmental-friendly and economical method to produce biodiesel from palm olein oil. Optimum conditions are calcium diglyceroxide $0.2 \%(\mathrm{w} / \mathrm{w}), \mathrm{Na}_{2} \mathrm{CO}_{3} 2.5 \%(\mathrm{w} / \mathrm{w})$, oil:methanol molar ratio of 1:6 and reaction period of $3 \mathrm{hr}$. at $65^{\circ} \mathrm{C}$. All the studied properties except kinematic viscosity agreed with the recommended levels by ASTM.

\section{ACKNOWLEDGEMENT}

This work was supported by the University of Ruhuna, Sri Lanka research grants RU/SF/ $\mathrm{RP} / 2011 / 1, \mathrm{RU} / \mathrm{SF} / \mathrm{RP} / 2013 / 3$ and RU/SF/ RP/2014/2. Authors would like to thank Prof K M Nalin deSilva, Sri Lanka Institute of Nanotechnology for providing SEM of the catalyst.

\section{REFERENCES}

ALAMU, O J; AKINTOLA, T A; ENWEREMADU, C C and ADELEKE, A E (2008). Characterisation of palm kernel oil biodiesel produced through $\mathrm{NaOH}$ catalysed transesterification process. Scien. Res. and Essay., 3 (7): 308-311.

ALBA RUBIO, A C; CASTILLO, $\mathrm{M}$ L; ALBUQUERQUE, $\mathrm{M}$ C; MARISCAL, R; CAVALCANTE Jr, $\mathrm{C}$ L and GRANADOS, $\mathrm{M} \mathrm{L}$ (2012). A new and efficient procedure for removing calcium soaps in biodiesel obtained using $\mathrm{CaO}$ as a heterogeneous catalyst. Fuel, 95: 464-470.

BASILO, DE L; SILVEIRA, E L C and TUBINO, M (2012). Determination of sodium, potassium, calcium and magnesium cations in biodiesel by ion chromatography. Anal. Chim. Acta., l718: 116.

BOEY, P L; MANIAM, G P and HAMID, S A (2009). Biodiesel production via transesterification of palm olein using waste mud crab (Scylla serrata) shell as a heterogeneous catalyst. Biores. and Tech., 100 (24): 6362-6368.
CHANTARA-ARPORNCHAI, S; LUENGNARUEMITCHAI, A and JAI-IN, S (2012). Biodiesel production from palm oil using heterogeneous base catalyst. Int. J. Chem. Mol. Nucl. Mat. and Metal. Eng., 6 (4): 321-326.

CHEN, G Y; SHAN, R; SHI, J F and YA, B B (2015). Transesterification of palm oil to biodiesel using rice husk ash-based catalysts. Fuel Proc. Tech., 133: 8-13.

DESHPANDE, $P$ and KULKARNI, K (2012). Production and evaluation of biodiesel from palm oil and ghee (clarified butter). Chem. and Proc. Eng. Res., 2: 2224-7467.

GRANADOS, M L; ALBA -RUBIO, A C; VILA, F; ALONSO, D M and MARISCA, R (2010). Surface chemical promotion of $\mathrm{Ca}$ oxide catalysts in biodiesel production reaction by the addition of monoglycerides, diglycerides and glycerol. J. Catal., 276: 229-236.

KESIĆ, Z; LUKIĆ, I; ZDUJIĆ, M; MOJOVIĆ, L and SKALA1, D (2016). Calcium oxide based catalysts for biodiesel production: a review. Chem. Ind. Chem. Eng. Q., 22 (4): 391-408.

KOUZU, M; KASUNO; TAJIKA M; YAMANKA, S and HIDAKA, J (2008). Active phase of calcium oxide used as solid base catalyst for transesterification of soybean oil with refluxing methanol. Appl. Catal. A: Gen., 334: 357-365.

KOUZU, M; YAMANAKA, S., HIDAKA, J and TSUNOMORI, M (2009). Heterogeneous catalysis of calcium oxide used for transesterification of soybean oil with refluxing methanol. App. Catal. AGen., 355: 94.

KOUZU, M; HIDAKA, J; WAKABAYASHI, K and TSUNOMORI, M (2010). Solid base catalysis of calcium glyceroxide for a reaction to convert vegetable oil into its methyl esters. Appl. Catal. A: Gen., 390: 11-18.

LAURA LEON, R; CABEZA, A; RIUS, J; MAIRELESTORRES, P; ALBA-RUBIO, A C and GRANADOS, 
M L (2013). Structural and surface study of calcium glyceroxide, an active phase for biodiesel production under heterogeneous catalysis. J. Catal., 300: 30-36.

LEE, H V; JUAN, J C and TAUFIQ-YAP, Y H (2015). Advancement in heterogeneous base catalyzed technology: an efficient production of biodiesel fuels. Renew. Energy, 74: 124-132.

LUKIC, I; KESIC, Z; ZDUJIC, M and SKALA, D (2016). Calcium diglyceroxide synthesized by mechanochemical treatment, its characterization and application as catalyst for fatty acid methyl esters production. Fuel, 165: 159-165.

MAYA, C Y; LIANGA, Y C; FOONA, C S; NGANA, M.; HOOKB, C C and BASIRON, Y (2005). Key fuel properties of palm oil alkyl esters. Fuel, 84: 17171720.

MORI, K; MATSUBARAM, H and KITAGAWA, K (2011). Study of biodiesel fuel production by calcium oxide catalyst. $22^{\text {nd }}$ International Fuel Production by Calcium Oxide Catalyst Conference.
NATIONAL RENEWABLE ENERGY LABORATORY (2008). Biodiesel Handling and Use Guide. $4^{\text {th }}$ Edition. http://www.osti.gov/bridge, accessed on 25 June 2016.

REYERO, I; ARZAMENDI, G and GANDIA, L M (2014). Heterogenization of the biodiesel synthesis catalysis: $\mathrm{CaO}$ and novel calcium compounds as transesterification catalysts. Chem. Eng. Res. E Design., 92 (8): 1519-1530.

SAGIROGLU, A; ISBILIR, S S; OZCAN, $\mathrm{M} \mathrm{H}$; PALUZAR, H and TOPRAKKIRAN, N M (2011). Comparison of biodiesel productivities of different vegetable oils by acidic catalysis. Chem. Ind. and Chem. Eng. Quarterly., 17 (1): 53-58.

SHARMA, Y C; SINGH, B and KORSTAD, J (2011). Latest developments on application of heterogenous basic catalysts for an efficient and eco friendly synthesis of biodiesel: a review. Fuel, 90: 1309. 